\title{
Professional Role of Tour Guides and Theoretical Consequences of Intercultural Communication
}

\author{
M. Dahlan Bahang \\ Universitas Negeri Makassar, Jln. Bonto Langkasa, Kampus Gunung Sari, Makassar, South Sulawesi, Indonesia \\ Basri Wello \\ Universitas Negeri Makassar, Jln. Bonto Langkasa, Kampus Gunung Sari, Makassar, South Sulawesi, Indonesia \\ Mansyur Akil \\ Universitas Negeri Makassar, Jln. Bonto Langkasa, Kampus Gunung Sari, Makassar, South Sulawesi, Indonesia
}

\begin{abstract}
Intercultural communication between tour guides and foreign tourists, taking place in a number of tourist attractions in Tana Toraja, Indonesia, is a form of communication used to share information from various cultures and social groups. This factual condition of intercultural communication proves that; Firstly, none of the five informants (tour guides) selected which duties to perform as explicitly mentioned in the first theoretical consequence of intercultural communication by Sunnafrank (1989, p.44). As mentioned in the first theoretical consequence of intercultural communication, although intercultural communication is difficult, tour guides are unlikely to avoid it because it is assigned by the company hiring them, in addition to the fact that they already have professional competence as a tour guide, mastering international languages, cultural product knowledge and information related to tourist destinations. Secondly, in the communication process, none of the tour guides and foreign tourists reduced their communication intensity despite finding negative results. These two facts are the characteristics of intercultural communication between tour guides and foreign tourists in Tana Toraja, Indonesia. In terms of linguistics, findings lead to verbal forms used, both as the consequences of language relativity as well as the preferences of cultural experiences of each foreign tourist.
\end{abstract}

Index Terms - intercultural communication, professional role of tour guides, theoretical implication

\section{INTRODUCTION}

In today's modern era, the development of information-communication technology and transportation enables people around the world to interact intensively. Intercultural contact is inevitable. The world has become what McLuhan (1964, p.33) called the "Global Village". This intercultural contact does not necessarily go smoothly as there are cultural differences between people who interact. These include differences in languages, norms, and expectations that complicate the communication between people from different cultures or nations.

Such interactions are made possible by increasing and unhindered human mobility. Humans can easily travel to different parts of the world to visit new places, experience new cultures, meet different people, and or explore business opportunities. In the dynamics of this relationship, there is an interaction, through which intercultural communication takes place. In the context of intercultural communication, an intermediary language is needed, known as lingua franca.

In practice, the role of English as a lingua franca is irrefutable. However, the complexity and fluctuation of intercultural communication situation cannot be easily overcome through the use of English. Various linguistic phenomena occur within the sphere of intercultural communication. The greater the intercultural differences are (and, therefore, the greater the difference in communication is), the more difficult it is to communicate. This difficulty can lead to, for example, more communication errors, more utterance mistakes, more misunderstanding, more misperceptions, and more frequent bypassing.

The greater the intercultural differences are, the greater the uncertainty and ambiguity in communication are. In the communication process, everyone will try to reduce this uncertainty in order to properly decipher, predict, and explain what they are communicating. Reducing uncertainty and ambiguity requires more time and effort for communication to be more meaningful.

The above paragraph shows that language is a reflection of culture. In other words, language represents certain characteristics of every culture. Therefore, languages of the world vary greatly in terms of their semantic characteristics and structural features. Characteristics of language, according to Sapir (1968, p.27), affect human cognitive processes. This underlies the fact that people who use different languages perceive and think about the world differently (language relativity).

In intercultural communication involving tour guides, verbal barriers in the form of polarization are still found. In this case, the reality is polarized. For example, a foreign tourist communicating with his guide polarized the following value: “...Ternyata, prosesi Rambu Solo' itu berbiaya tinggi. Apa ini tidak berarti pemborosan?” ("... Apparently, 
Rambu Solo' is a very expensive ceremony. Does this not mean waste? "). This example of verbal interaction shows the tendency of the tourist to take increasingly extreme position in terms of categorizing Rambu Solo' ceremony (polarization).

Another barrier in verbal interaction of intercultural communication can indicate indiscrimination. The term "indiscrimination" rests on the principle that verbal formulation can be trapped away from the undoubted potential of distinctive characteristics. The form of verbal formulation of indiscrimination is illustrated in the choice of the word "keras" (rough) in: “...Pak Carles Hutagalung itu orangnya keras ya?” ("... Mr. Carles Hutagalung is a rough man huh?"). The information supporting the statement includes only information about Carles Hutagalung's ethnicity who comes from Batak Tribe, and visual information obtained from the acquaintance process that lasted for 20 minutes. Although it seems easy to overcome, this symptom can generally be avoided when it has become a barrier to intercultural communication.

In order to maximize interaction, in intercultural communication, as in other forms of communication, each participant in the communication process will undoubtedly seek to maintain interaction. The thesis presented by Sunnafrank (1989, p.44) implies that there are three implications in intercultural communication. First, someone will interact with others that he/she expects will give a positive result. Since intercultural communication is difficult, then perhaps some people will avoid it. Thus, for example, someone will choose to speak with others who have much in common with him/her rather than with those who are very different from him/her. This principle is certainly not applicable in intercultural communication involving tour guides. Tour guides, in performing their duties professionally, cannot select which duties to perform as indicated by Sunnafrank. Any tour guide, whatever their cultural backgrounds, should be able to establish communication professionally.

Second, if intercultural communication gives positive results, every participant in the communication process will continue to engage in it and as much as possible improve the quality of their communication. However, if the result is negative, participants in the communication process will tend to reduce the intensity of communication. The negative prospect of this principle can not necessarily be applied due to professional role of tour guides. Even if encountering any communication barriers, a tour guide should be able to organize and explore his/her competence as a professional guide to achieve a positive communication situation.

Third, participants in the communication process will make predictions about which behaviors will induce positive communication results. For that, participants in the communication process will try to predict the results of their communication through, for example, the choice of topics, positions to be taken, nonverbal behaviors to be displayed, and so on. Participants then do what they think will give positive results and try to avoid what they think will lead to negative results. In this context, a tour guide should adorn his/her communication competence with this kind of prediction skill.

The profession of a tour guide in the domain of tourism has been so rapidly developed in the last two decades. In Indonesia, as a leading development domain in every period of national leadership, the development of this profession in tourism has reached the stage of establishing nationally certified competence standards since 2012. For this purpose, the central and regional governments, through their relevant networks (Ministry and Department of Tourism), actively organize education and training for this profession.

In fact, in general, the certification of every profession that demands standardized competence has been required through the National Agency for Professional Certification (BNSP). Professional tour guide certification is specially organized by the Institution of Certification for Tourism Professions (LSP) spread throughout Indonesia on the basis of BNSP license. Since it is urgent and relevant to maintain and improve the professional competence of the tour guides, this profession is licensed to empower it through a professional association called the Indonesian Tourist Guide Association (HPI). This association also provides education and training of tour guides.

The development of the professional competence of tour guides suggests that a number of principles in intercultural communication theoretically confirmed as imperative theses seem to fall and require further arrangement. The three theoretical consequences of intercultural communication by Sunnafrank (1989, p.44) seem to no longer be able to explain the empiric reality of a tour guide as a competent professional. In fact, empiric reality of professional tour guides oppose the first and second principles of intercultural communication consequences by Sunnafrank (1989).

The taxonomy process of the objects of this research lies in the concept of Communication as the grand theory, the concept of intercultural communication as the middle theory and linguistic relativity as the operational theory to solve language phenomena; verbal forms in intercultural communication between tour guides and foreign tourists:

\section{Intercultural Communication and Theory of Language}

Intercultural communication is communication that occurs between people who have different cultures. McLuhan (1964, p.33) states that the world today has become a "Global Village" so that interconnection becomes absolute. This intercultural contact does not necessarily go smoothly as there are cultural differences between people who interact. These include differences in languages, norms, and expectations that complicate the communication between people from different cultures or nations.

Communication is a process of using signs and symbols that bring meaning. Thus, the continuity of communication depends on the various signs and symbol systems used. This principle reveals the gap where the intermediary language (lingua franca) occupies an important position in intercultural communication. The lingua franca used in intercultural 
communication might be a language coming from the culture of one of the participants in the communication process or not be the language spoken by both parties in the communication process.

Language studies can be initiated when the participants have the same interpretation of the meaning of symbols used in intercultural communication. The situation implies that intercultural communication can only take place and can be said to achieve its purpose if the cultural backgrounds of each participant in the communication process support the symbol systems used. The situation arises from the basic assumption that differences in communication are profound and related to semantics (Wierzbicka, 1991a, p.69).

The most common issue in terms of meaning in intercultural communication is when there is a difference in giving meaning to symbols due to different cultural backgrounds. Meaning is reality, while reality is encoded into culture (language). The phenomenon behind the premise emphasizes that there is not only a space for language study in intercultural communication, but intercultural communication is really a matter of language and culture. (Wierzbicka, 1991a, p.69).

The exposition above is an index that can lead to an understanding that the root of intercultural communication is language, especially sociolinguistics. The phenomenon of language in intercultural communication is even seen as a treasure that presents the richness of linguistics, both as art and science. Sapir (1968, p.19) has proved that there is a convergent perspective through the study of the phenomenon of language and culture, which is known as cultural theory of language.

Sapir $(1968,19)$ emphasizes that the background of the linguistic (or grammar) system of any language is that it is not only a reproduction tool for conveying ideas, but also the one that forms ideas, forms and guides individual mental activity, for analyzing impression, synthesizing mental activity in communication. The formulation of ideas is not merely an independent process and a rational activity, but a distinct grammar different among other grammars.

Hence, language is cultural. In fact, language rules vary widely from one culture to another. Therefore, individuals from different cultures will be different in the way they perceive the world. For example, some languages have so many terms for 'snow', while some other languages do not even have a single term, especially for those the speakers of which have never seen it.

According to Sapir (1968, p.37) and Whorf (1956), the language of a culture will be directly related to how we think in the culture. This assumption is in line with the anthropological view of cultural relativity, which states that since different cultures have different languages and different worldviews, then they also have different beliefs and values.

\section{Theory of Intercultural Communication}

Referring to the discussion of the nature of communication, we know that identification of similarities is an important aspect of the process of information exchange. In accordance with the concept of "overlapping of interests", similarity is a sort of framework in communication. In order for the parties involved in the communication process to understand each other and thereby communicate effectively, they must have something in common in terms of background and experience. The term commonly used to describe similarities between parties in the communication process is "homophily". In other words, homophily is the degree of similarity in certain things such as beliefs, values, education, social status, etc., between two interacting individuals.

This belief makes it possible to achieve the same perception and meaning of an object or event. However, what about the intercultural communication that is based on the assumption of cultural differences? In terms of the basic principles of communication explained earlier, these differences would tend to reduce or inhibit the occurrence of effective communication. If the messages conveyed transcend cultural boundaries, what the sender means, in a certain context, will be interpreted in another context by the receiver. In this intercultural situation, there will be little or no "coorientation, which is a requirement for communication in general". This co-orientation means that between the two communicating parties there should be a similarity in terms of orientation to the topic of their communication (Saral, 1979, p.395). It can also be said that based on the principles of homophily, people tend to interact with others whom they have something in common with in terms of social characteristics.

Dodd (1982, p.168-170) proposes a classification of homophily dimensions as follows: (1) Homophily in appearance; (2) Homophily in background; (3) Homophily in attitude; (4) Homophily in value; (5) Homophily in personality. However, in terms of the importance of intercultural communication, differences do not rule out the possibility of communication between individuals or cultural groups. Differences are even seen as the framework or matrix in which communication occurs. In this respect, the theory presented by Grannovetter (1973) is relevant: "The strength of weak ties suggests the importance of heterophily relations in the exchange of information. In communication, there seems to be a balance between similarity and difference between what is considered as usual and new.

A basic proposition states that the power of information exchange on communication (between two people) has to do with the degree of heterophily between them. In other words, people will receive new, informational things, through weak ties. In line with the above concept, there is a concept of equifinality in system theory that in any given system, the same goal can be achieved, although different starting points and processes have been employed. Similarly, in terms interpersonal relationship, an idea mentions that two people will act the same even if they have received or experienced a very different stimuli (Bennet, 1998, p.117).

In relation to the foregoing, Dood (1982, p.176-177) holds that in communication, the essence of a social system can affect the principle of homophily in the search for information, especially in modern society. In that view, it is 
emphasized that people are looking for technically more skilled individuals who can show an increasing degree of innovation. In this case, such a heterophile situation may occur if difference is not too large, known as optimal heterophily. Tolerance to this difference is possible, because in the relationship of two people who are perfectly homophile, their knowledge of innovation will be the same. Ideal circumstances in polarized information acquisition include; heterophile in terms of knowledge, but homophile enough in terms of characteristics or other variables, such as socioeconomic status.

Thus, if the potential effect of these differences on communication is recognized or acknowledged, other problems may lie in the means, strategies or techniques of communication employed. In intercultural communication, individual differences can be made bigger by cultural differences. The perception of these cultures is the starting point of the most basic assumption of intercultural communication, namely the need to recognize and acknowledge differences to be bridged through communication.

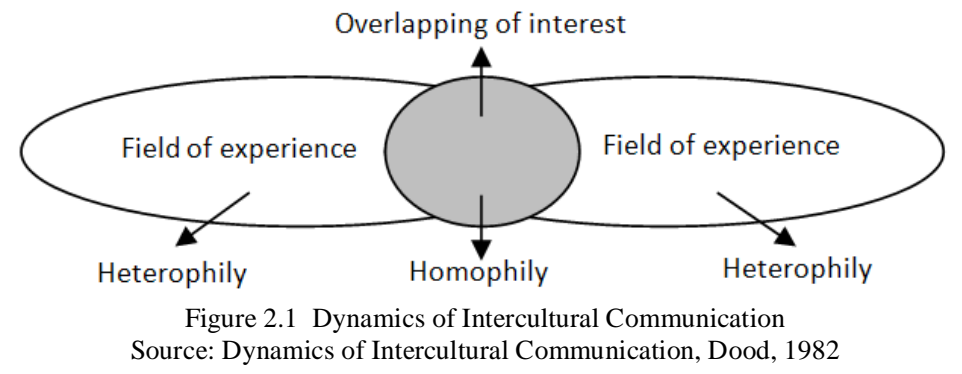

\section{Communication as Convergence Process;}

When related to symbolic interactionism of the dynamic and ongoing process of social interaction, there is a communication model that views communication process as an exchange of and sharing of information over a period of time. With this communication model, an approach, which is not bound to the rules or boundaries of a particular culture, is achieved, but can describe the reality of society.

Communication in this case is seen not as a communication from the sender to the receiver, but as a circular or cyclical communication. Parties involved in the communication process alternate roles as senders or receivers termed as transceivers, until finally achieving goals and mutual interests or understanding. Thus, communication always implies the existence of interconnectedness.

\section{Verbal Language in the Context of Intercultural Communication}

Both verbal and nonverbal languages as a form of message used by humans to make contact with the reality of their environment have similarities; (1) Using symbol system; (2) produced by individuals; (3) Others also give meaning to the symbols produced.

Based on this similarity, intercultural communication can be interpreted as a process of mutually giving meaning to the symbols conveyed between interacting individuals. Sarbaugh (1979, p.72) attempts to relate this process with the notion of communication. He defines communication as the process of using signs and symbols that bring meaning to others, as the following assumptions: (1) The continuity of communication depends on the various signs and symbol systems used; (2) Communication takes place only when the participants have the same interpretation of the meaning of symbols used in intercultural communication; (3) The most common issue in terms of meaning in intercultural communication is when there is a difference in giving meaning to symbols due to different cultural backgrounds.

Signs and symbols are the tools and materials used in interaction. The ability of human beings to use symbols makes them unique, which distinguishes them from other living beings. However, this unique ability and the process of performing a truly complex symbolization are usually underestimated, except in the face of difficulties, after which succeeding in finding "the right words" to describe something.

The discussion of the concept of symbols must begin with an understanding of the concept of signs. A sign is an element used to represent another element. All things used as a sign are different from the things they represent. Faules \& Alexander (1978, p.28-30) classify the signs into: (1) natural signs, and (2) artificial signs. Natural signs are physical phenomena used to represent other phenomena. For example, the leaves are dry and falling, or the cold indicates the beginning of autumn. Artificial signs are phenomena created to represent other phenomena, for example, traffic lights that indicate when to start or to stop driving.

The main difference between natural signs and artificial signs lies in their basic nature. Natural signs are active and artificial sign are interactive. Active signs are used for personal interpretation, whereas interactive signs used by two or more people are considered to have been able to represent something. For example, someone shows us that an orange with thin, not hard and smooth skin, will taste sweet and watery. It turns out that we can prove it by choosing and eating an orange that has these signs. This experience can be passed on to others so that they are not wrong in choosing oranges. The way to do so is not to bring oranges to everyone, but simply using words (artificial signs) to explain the signs to others (interaction). For ourselves, the orange itself is physically an active natural sign, used to make personal interpretations. For the next person, the orange is already an artificial sign. 
Artificial signs can be divided into signals and symbols. Signals are artificial signs that generate predictable responses by receivers. Signals are artificial signs that are expected to result in a mutually recognized response. For example, traffic lights showing the red light on will produce an automatic response to anyone who sees it to stop driving or at least a prediction that they will stop driving. Thus, in this case, it is clear that people have been conditioned to respond equally to a signal.

As other kinds of artificial signs, symbols generate degrees of uncertainty because of the ambiguity experienced by the receiver and thus ruling out the possibility of prediction of the response to them. The response to symbols is learned but not conditioned. The learned response is always based on the unique experience of each person. The application of the learned response can be described as stimulus-organism-response (S-O-R). In contrast, conditioned response describes the state of the stimulus to the response (S-R). In other words, filtering the stimulus through the response is to distinguish symbols from signals. Signals generate conditioned response and symbols result in learned response.

Such a difference leads to the conclusion that all artificial signs begin as symbols and some of the symbols are repeated and reinforced repeatedly to form signals. As a result, the difference between signals and symbols must be based on the functional response rather than on the elements and the inherent nature that they contain. Therefore, it is not possible to compile a list of signs that can be classified as signals or symbols. In this case, the context in which sign s are conveyed is of paramount importance in determining the interpretation of the person of them (Figure 2).

The following scheme presents the categorization and differentiation of signs:

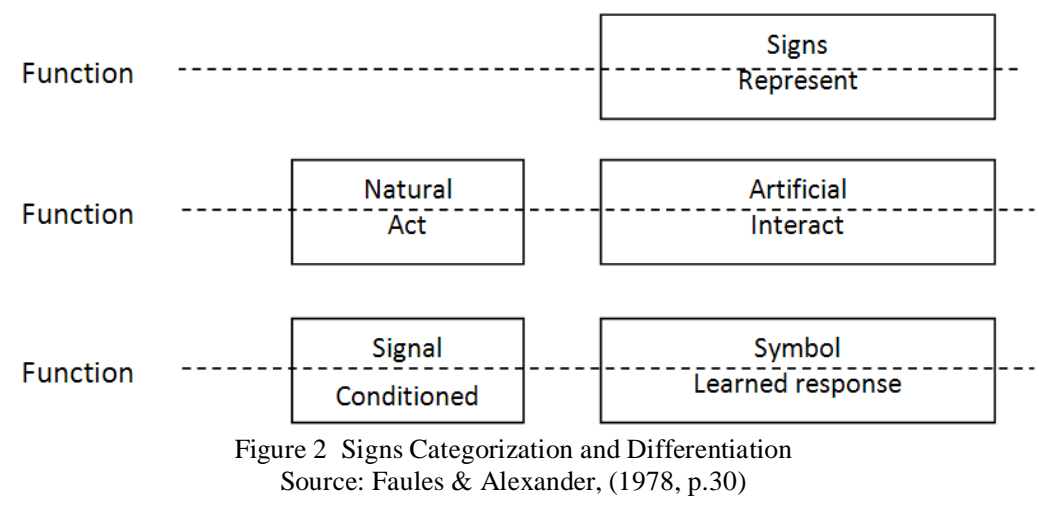

Referring to the scheme, symbols can be said to have the following qualities: (1) A product of human activities; (2) Representing various concrete and abstract parts of reality; (3) Having rules for their use; (4) Being arbitrary and due to being merely representative of something else beyond them, their meaning may vary for others.

Symbols can be classified into; (1) Verbal symbols, as spoken and written words (2) Non-verbal symbols, as a form of language/behavior without words. Therefore, the use of symbols in the process of intercultural communication can be viewed from the dimensions of verbal and non-verbal processing.

The most common form of human verbal language is the spoken language. Written language is a way of recording spoken language by making signs on paper as well as on copper sheets and others. This writing allows humans to record and store knowledge so that it can be used in the future or transmitted to the next generations.

Language consists of symbols (words) and rules of use, so in learning another language (second language), the two things must be taken into consideration. In addition to words, the rules also differ in each language. Spoken language consists of symbols and sounds that can represent objects, feelings, and ideas.

Therefore, human skills and abilities affect the use of sounds and signs in place of objects and feelings. They include four activities, namely receiving, storing, processing and disseminating symbols. It is wrong to say that words have meaning in themselves. In this case, what has meaning is the person who uses them. Words simply generate meaning to those using them. Therefore, words can be the same, but they are different in meaning. These basic assumptions suggest that there is no such thing as "real" meaning because everyone, through his or her personal experience, determines the meaning of a symbol subjectively. Humans can have the same meaning only to the extent that they have the same experience or can anticipate the same experiences.

Culture teaches people to name things, people, and ideas in terms of their practice, use and importance. Usually, important things are given a specific name or label. For example, in a community who consume rice as staple food, there are special words that describe different kinds of rice. Another example, Eskimos have a variety of special terms for different types and forms of snow. Similarly, French people have very detailed and varied names to describe various foods and wines.

According to Sapir (1968, p.19) and Whorf (1956), language serves not only as a mechanism for communication, but also as a guide to social reality. In other words, language not only describes perceptions, thoughts and experiences, but also determines and shapes them. Such a principle is not much different from the subject of sociolinguistic studies (sociology of language) that examine the relationship between language structure or speech performance and social structure (in the form of interaction). 


\section{RESEARCH METHOD}

The primary data was collected through interviews. Meanwhile, the secondary data was collected by recording the conversation between tour guides and foreign tourists at natural and cultural attractions in Tana Toraja, and through document review. Data sources include; five tour guides and twelve foreign tourists coming from different countries.

\section{DISCUSSION}

Intercultural contact put forward differences in language, norms, and expectations so that they are theoretically identified as communication barriers. Sunnafrank (1989, p.44) conceptually determined the barriers to intercultural communication into three consequences of intercultural communication. However, the factual reality of intercultural communication of tour guides shows different characteristics and tendencies. This research directs its purpose to this issue by utilizing seven indicators of study. Determination of the study at the same time indicates the presence of tendencies different from the established theoretical consequences.

Referring to the definition proposed by Lauring, Jakob and Selmer (2011), Liliweri (2011), intercultural communication between tour guides and foreign tourists, Tana Toraja, Indonesia, is a form of communication used to share information from various cultures and social groups. This factual condition of intercultural communication proves that; firstly, none of the five informants (tour guides) selected which duties to perform. They will guide tourists of any nation in the name of professional duties. This is different from the first theoretical consequence of intercultural communication by Sunnafrank (1989, p.44). Similarly, all foreign tourists selected their guide without any consideration.

As mentioned in the first theoretical consequences of intercultural communication, although the intercultural communication is difficult, the tour guides are unlikely to avoid it because it is assigned by the company hiring them, in addition to the fact that they already have a professional competence as a tour guide, mastering international languages, cultural product knowledge and information related to tourist destinations. Secondly, in the communication process, none of the tour guides and foreign tourists reduced their communication intensity despite finding negative results. These two facts are the characteristics of intercultural communication between tour guides and foreign tourists in Tana Toraja, Indonesia. It seems that the factual condition that characterize the object of the study suggests its implication of opposing to two of the three consequences of intercultural communication by Sunnafrank $(1989$, p.44).

The distinctiveness of intercultural communication setting between tour guides and foreign tourists in Tana Toraja, Indonesia, although not consistent with the first and second theoretical consequences of intercultural communication, still shows some findings of communication barriers in verbal forms. The findings of these verbal forms are present as the consequence of language relativity as well as the preferences of the cultural experiences of each foreign tourist. These verbal forms maximize their influence on the communication process between both parties and indicate barriers to intercultural communication. Of the seven theoretical indicators used in the identification of the factual problems of this research, only six were found indicating communication barriers that were dominantly played by foreign tourists. The seven theoretical indicators used in the identification of the factual problems of intercultural communication are all things that hinder the occurrence of effective communication (Chaney and Martin, 2014, p.11).

The forms of intercultural communication barriers found include; (1) Two forms of verbal polarization. Both are viewed in socioeconomic perspective. Verbal polarization is present as a form of comparison between the realities of Ma'nene ritual in Tana Toraja, observed with knowledge possessed by informants. This is the managerial aspect of organizing the cultural event. To the informants' knowledge, interesting cultural events such as Ma'nene ritual should get financial support from the local government. This is deemed necessary because the local government has already scheduled it in the regional tourism calendar, and because the informants sees the local government interest in this context. Otherwise, the informants would consider the Ma'nene ritual to be wasteful, as in the following excerpts of the interview:

"... according to your explanation, this event (Ma'nene) is a family event, which is to clean and replace the ancestral body clothes by the descendants. Is the entire cost of Ma'nene's party borne by the descendants of the family? .............."

"...I think, because in this modern era, the tradition has been used as a tourist attraction by the government, the government participates to finance such cultural events. But if not and self-financed by family members, does not this mean waste?" (April 12, 2016, 11: ${ }^{.0} \mathrm{am}$ ).

(2) Intentional orientation; There are two types of Intentional Orientation found, seen from psychological condition. An informant, a female tourist, experienced a panic attack when looking at creepy pictures. Another informant was a male tourist who was not pleased to be in a traffic jam while traveling to Kampung Lolai tourist attraction known as "Land in the Cloud". Cultural experience serves as a reference for Mrs. "M"'s reaction. Thus, photographs of the deceased's body considered creepy actually serve only as a mere stimulus. Similarly, the meaning of the verbal symbol in Mr. "EK"'s statement is a derivation of cultural experience. Traffic congestion is a stimulus. The two verbal forms expressed by both informants are the apologies of their own psychological conditions, as the following data reveals:

"...I don't want to see this picture.... (Mrs. "M" screamed as she threw a picture of the deceased's body in the Rambu Solo' ritual she had just seen). (June 27, 2016, 13: ${ }^{10} \mathrm{pm}$ )

"... we should turn to other attractions. The situation is getting less comfortable." (26 April, 2017, 10: ${ }^{00}$ am). 
(3) Description and inferention; Data on Description and Inferention appears with non-figurative-non persona language background and others with literary style. The two types are very different but show the effort to show the quality and weight of strong inference. Through its linguistic capacity as a cultural experience, the tendency to build reality into the structure of scientific logic is the workings or language skills of informants as academics in shaping the reality of the Ma'nene tradition they perceived. Similarly, the inference form of description and inferention in literary language is the ability and the workings of an artist's language in shaping the reality of Kete 'Kesu figuratively, as the following data presents:

"... Yes, I must accept that fact as a proven fact through my vision. Therefore, I also mention that although it is still difficult to establish the logical structure, but because I witnessed it myself, then I must accept it as fact. At that time, even my body was shaking and sweating watching it. So fantastic! (April 28, 2017, 11: $:^{25}$ am).

"...of course only the word "fantastic" I can say to package and legitimize the fact that a pair of corpses are able to walk by themselves to their graves after they have been cleaned and changed. Because only able to annotate the facts into a word "fantastic" then, meaning and explanation more than that, I have not get. You are right; it is an inferential statement that does not support descriptive logic." (April 28, 2017, 11: $:^{35}$ am).

"... for me everything is a work. It could be a human work, it could be a work of nature or god. Therefore, when witnessing Kete 'Kesu, I immediately chuckled in awe. Consciously or unknowingly, intentionally or unintentionally, in my opinion, Kete 'Kesu is a masterpiece of Toraja People. My imagination even captures the message that the great work (Kete 'Kesu) is about humanity. (April 28, 2017, 21: ${ }^{00} \mathrm{pm}$ ).

"... If so, Tongkonan for the Toraja People, is not merely a place to live. Moreover, Tongkonan represents the life guidance for Toraja people. Which means the houses are not shaped Tongkonan here and there, not the original Toraja?

"... as I make that statement, my focus is the fact of the Torajans who deeply respect the noble values of their culture and religion and the facts about the Tongkonan house that contain the noble values of culture and religion as well as the facts about the condition of the houses in this city (Makale) which is dominantly modern and only a few form Tongkonan." (April 29, 2017, 21: $\left.:^{15} \mathrm{pm}\right)$.

(4) Evaluative error pattern; The verbal form of Evaluative Error Pattern comes with a tendency to bypass in evaluating reality. This is based on the explanation received about the values contained in Tongkonan as objects of Toraja cultural material. The informants tried to understand that Tongkonan contains substantial meanings that provide guidelines of the ethical-religious and social life of Toraja people. The verbal form of Evaluative Error Pattern is based on differences in the informants' cultural perceptions, causing differences in interpreting information about the Tongkonan concept provided by the tour guides. This communication barrier by Chaney and Martin (2004) is referred to as an obstacle arising from differences in cultural perceptions that individuals have about something in the communication process, as the following data illustrates:

"... If so, Tongkonan for Toraja people, is not merely a place to live. More than that, Tongkonan represents the guidelines of life for the people of Toraja. That means the houses are not shaped Tongkonan here and there, not the original Toraja huh? (April 29, 2017, 11:00 pm).

(5) Language relativity; The verbal form of language relativity embodies its indication through the six verbal forms found as evidence of the nature of language. Languaage relativity, in this case is relevant with the nature of the language referred to as arbitrary by Ferdinan De Saussure (1966). Through the Signifiant and signifie dichotomy, De Saussure (1966, p.67) asserts the absence of a mandatory relationship between language symbols (in the form of sounds) and the concept or meaning referred to by a symbol.

(6) Static evaluation; The form verbal of static evaluation comes from psychological condition. The psychological condition underlying the presence of the verbal form of static evaluation can be explained through the thought of Triandis (1994) that the relationship between culture and human development includes the tendency to form psychological condition such as disappointment. The cultural experience of the informants does not tolerate the complained incident so that their statements serve as an extended reaction with anger over the treatment they receive, as the following data illustrates:

"... I'm not comfortable with that second driver. Just now, when about to leave, he was shouted almost right in my ears, telling the tourists to get on the bus. I think that attitude is inappropriate and makes me uncomfortable. Please transfer me to another bus." (June 27, 2017, 11:20 am).

Indiscrimination; the verbal form of indiscrimination occurs from the informants' statements followed by a tendency to feel annoyed and disappointed. Psychological condition of being "disappointed" allows the presence of the verbal form of static evaluation, the mechanism of which is very possible for anyone. Every human being, with any cultural and linguistic backgrounds, has his or her own way of carrying out the mechanism of indiscrimination thinking. It can be explained through the thought of Triandis (1994) that the relationship between culture and human development includes the tendency to form psychological condition such as anger or disappointment. In terms of the cultural experience of informants, an incident should have not happened if the hotel staff was disciplined in performing their duties. Cursing and swearing as habits of people in developing and developed countries are a way to vent disappointment, as the following data shows:

"... My red-colored bag is not on the bus! I ask the hotel clerk, do you see my bag put into the trunk of the bus or left at the hotel? He just answered did not know. Supposedly the hotel clerk informed us of every guest's belongings put in 
the bus luggage. Hotel services should include surveillance of guest goods as we are still staying at the hotel. I am fed up with this. shit! third country service. "(April 26, 2017, 10:00 am).

\section{CONCLUSION}

The seven verbal forms found indicating barriers to intercultural communication occur in empirical realities that deny the first and second theoretical consequences of intercultural communication by Sunnafrank (1989, p.44). This is a theoretical implication of this research. All the data related to verbal forms found is a reinforcement and reaffirmation that the involvement of differences in language, cultures and expectations in naming reality as an effort to communicate the intent and purpose of communicant and communicator in turn is still a significant barrier to intercultural communication between tour guides and foreign tourists.

\section{REFERENCES}

[1] Bennett, Milton, (1998). Basic Concepts Of Intercultural Communication: Selected Readings. Yarmouth: Intercultural Press.

[2] Chaney, Lillian, H. dan Martin, Jeanette, S. (2014), Intercultural Business Communication, Pearson Publishing Ltd. USA.

[3] Dodd. Carley. H,. (1982). Dynamics of Intercultural Communication. Dubuque, Wm .C. Brown Company Publishers.

[4] Faules, D. F. and Alexander, D. C. (1978). Communication of innovations: A cross-cultural approach (2nd edition). New York: The Free Press.

[5] Granovetter, S., Mark. (1973). The Strength of Weak Ties, American Journal of Sociology, Volume 78(6) May, p.1360-1380.

[6] Lauring, Jakob, and Selmer. (2011). Multicultural Organizations: Common Language, Knowledge Sharing and Performance, Personnel Review 40 (3), p.324-343.

[7] Liliweri, Alo. (2011). Komunikasi Serba Ada Serba Makna. Jakarta. Kencana. Prenada Media Group.

[8] Sapir, Edward. (1968). Culture, Language and Personality, University of California Press.

[9] Saral, T., B., (1979). Intercultural Communication Theory and Research: An Overview of Challenge and Opportunities, Communication yearbook.

[10] Sarbaugh, L. E., (1979): Intercultural communication. Publisher, Hayden Book Company, Original from, the University of Michigan.

[11] Sunnafrank, Michael. (1989). Uncertainty in interpersonal relationships: A predicted outcome value interpretation of Gudykunst's research program, Annals of the International Communication Association, Routledge.

[12] Whorf, Benjamin Lee. (1956). Language, Thought \& Reality. Cambridge, MA: MIT Press.

M. Dahlan Bahang was born in Enrekang, South Sulawesi, Indonesia on December 15, 1965. He is a doctoral candidate of English Education Department at the State University of Makassar. He completed his bachelor's and master's degree in English Education Department with a focus on writing skill. He is a teacher at STKIP-YPUP, Sulawesi Selatan.

Basri Wello was born in Maroanging, Enrekang, Makassar, Indonesia on November 05, 1952. He is a professor of English Education at English Department of State University of Makassar, Indonesia. He graduated his S1 from IKIP Ujung Pandang in 1977 , S2 from the Cansas University of US in 1987 and graduated his doctoral program from Hasanuddin University, Makassar, Indonesia in 1999.

$\mathrm{He}$ is an Education Specialist with over 20 years of experience in the education sector in Indonesia. His various areas of expertise include Curriculum design, design and establishment of the baseline for the school system in Indonesia, school program assess ment and evaluation, pre-service and in-service teacher training, school accreditation, teacher certification, and higher education management. In addition, he also an advisor for the planning and implementation of school development programs as well as facilitating community participation at the city and school level from 2008-2012. He was responsible for controlling, evaluating and providing service and technical assistance to 347 private higher education institutions in regional IX Sulawesi. Since 2006 he has been a chairperson for Makassar City Education Council and for the last few years as an Education Specialist, he has been largely involved in Project evaluation funded by USAID namely MBE final Evaluation ( SCECID, USA), DBE Mid-term Evaluation ( TMG, USA), DBE Final Evaluation (JBS, USA), Aceh Polytechnique Evaluation and A Gapp Analysis of Teacher Training Institute in Indonesia ( JBS, USA), Indonesian Tracer Study (JBS-USAID), USAID PRIORITAS final Evaluation (MSI-MESP).

Mansyur Akil an Education specialist with over 20 years of experiences in education sector in Indonesia. He is a senior lecture on: Language philosophy, Theory Construction and Model Building, Translation, System Theory and Research Methodology. For the last few years he also has published several articles such as systems Approach (SA) to curriculum Development 2016, Aspect, Adverb of time and tenses in English and Indonesian 2016, Translation Errors made by Indonesia-English Translators in Crowd Sourching translation application 2017, looking at the shared conception of teaching literature in an Indonesian ELT Setting 2018, and verbal communication in cross-cultural interaction (A case study of tourist guiders in Tana Toraja, Indonesia) 2018. 